\title{
Effects of ROI definition and reconstruction method on quantitative outcome and applicability in a response monitoring trial
}

Nanda C. Krak¹, R. Boellaard1', Otto S. Hoekstra1', Jos W. R. Twisk², Corneline J. Hoekstra ${ }^{1}$, Adriaan A. Lammertsma1

${ }^{1}$ Clinical PET Centre, VU University Medical Centre, Amsterdam, The Netherlands

${ }^{2}$ Department of Clinical Epidemiology and Biostatistics, VU University Medical Centre, Amsterdam, The Netherlands

Published online: 26 August 2005

(C) Springer-Verlag 2005

Eur J Nucl Med Mol Imaging (2005) 32:1245

DOI $10.1007 / \mathrm{s} 00259-005-1926-5$

\section{Eur J Nucl Med (2005) 32:294-301}

The following acknowledgement should have been part of the original article:

Acknowledgement. The authors would like to thank Dr. Johan Nuyts from the Department of Nuclear Medicine, University Hospital Gasthuisberg, Leuven, Belgium, for providing the semi-automatic program that was used to draw the three-dimensional regions of interest.

The online version of the original article can be found at http://dx.doi.org/10.1007/s00259-004-1566-1

Adriaan A. Lammertsma (-)

Clinical PET Centre,

VU University Medical Centre,

Amsterdam, The Netherlands 